\title{
Effects of marine fuel sulfur restrictions on particle number concentrations and size distributions in ship plumes in the Baltic Sea
}

Sami D. Seppälä et al.

Correspondence to: Sami D. Seppälä (sami.seppala@fmi.fi)

The copyright of individual parts of the supplement might differ from the CC BY 4.0 License. 


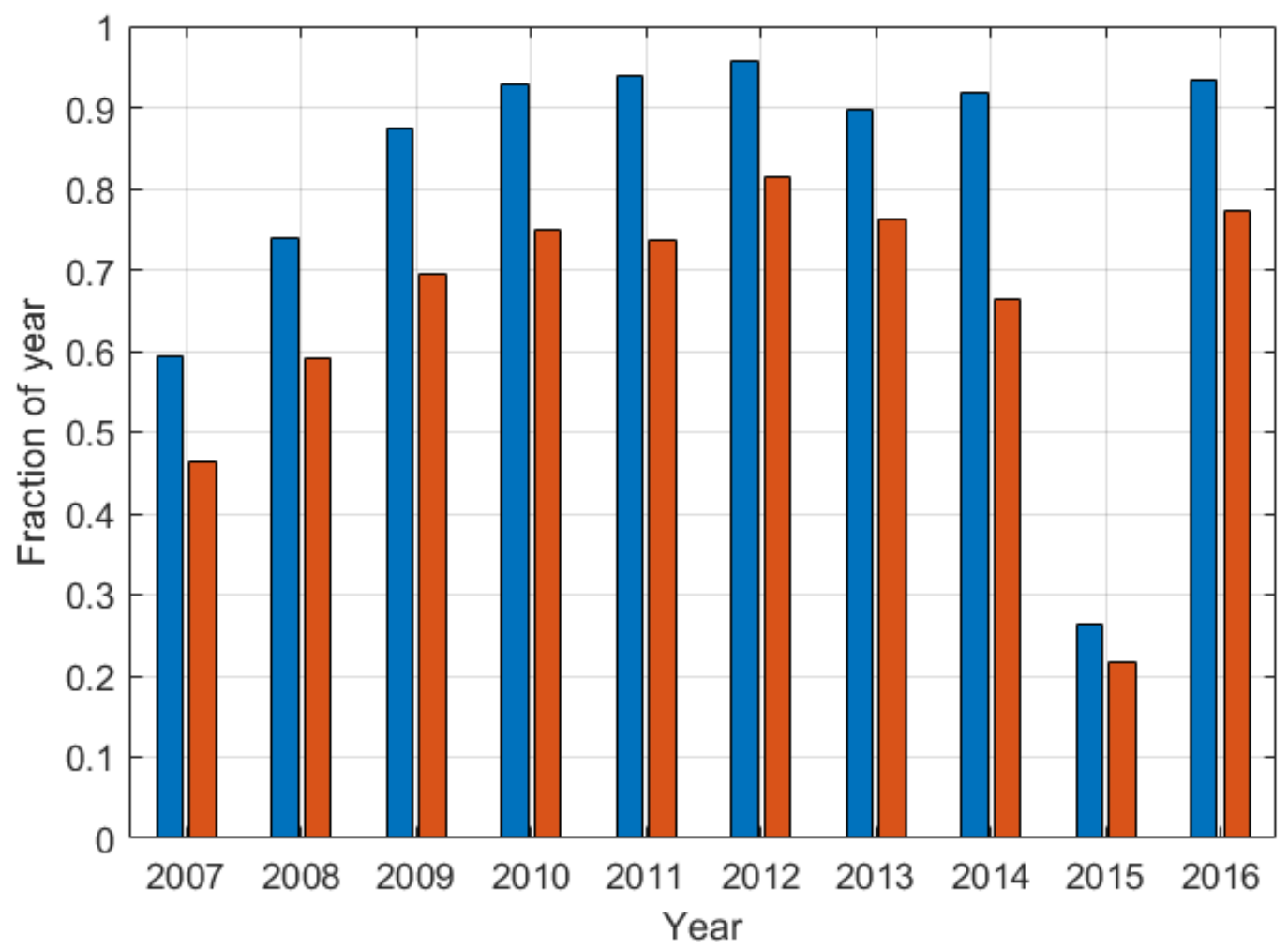

Cleaned data

Valid data

Figure S1: Coverages of cleaned and valid periods of the DMPS data for each year (2007-2016). 

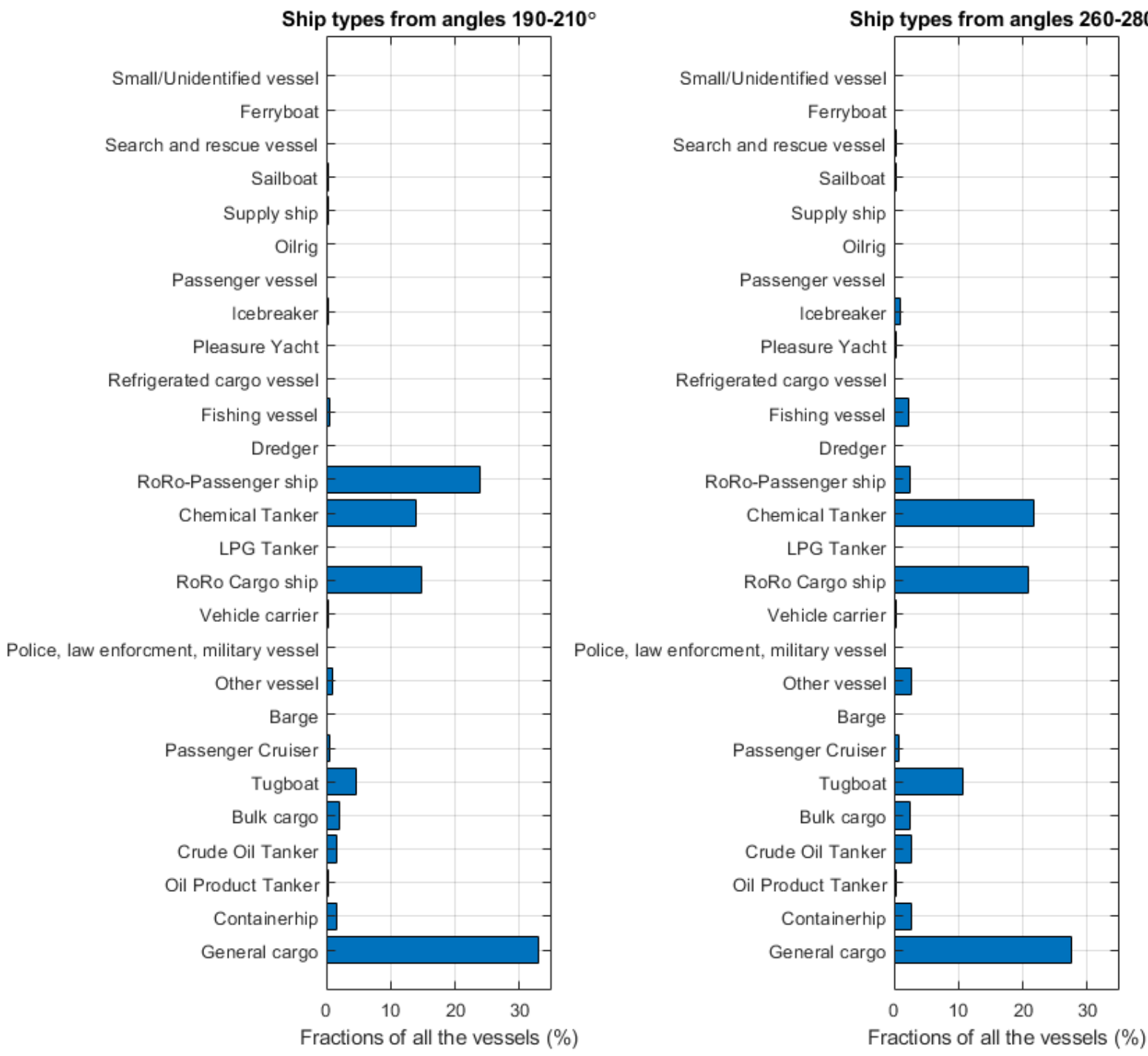

Figure S2: Fractions (\%) of different ship types from angles $190-210^{\circ}$ and $260-280^{\circ}$. LNG and RoRo stand for liquefied petroleum 5 gas and Roll on roll of, respectively. 

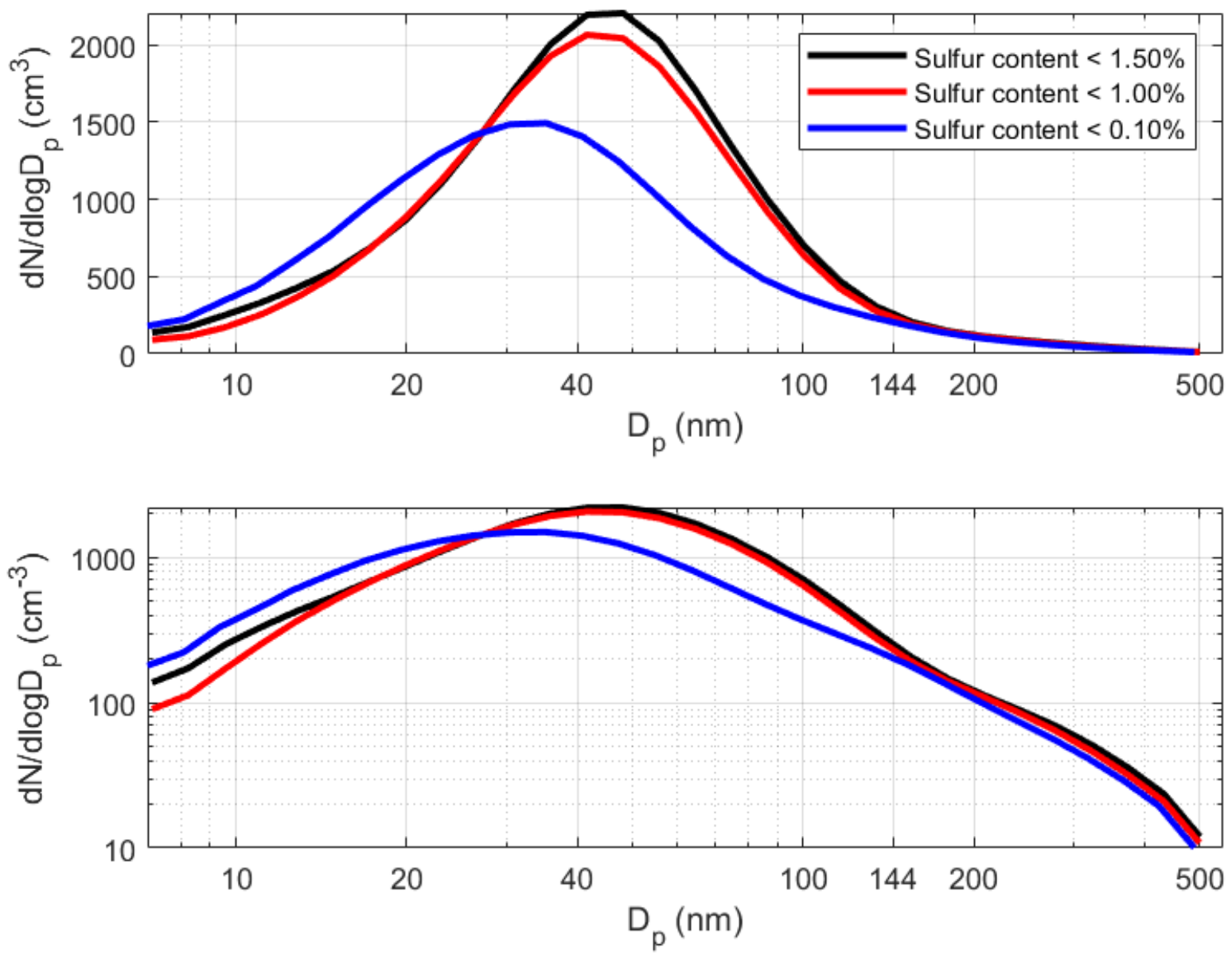

Figure S3: Average number size distributions of the valid plumes $\left(\mathrm{NSD}_{\mathrm{pl}}\right)$ during the different fuel sulfur content (FSC) restrictions. 

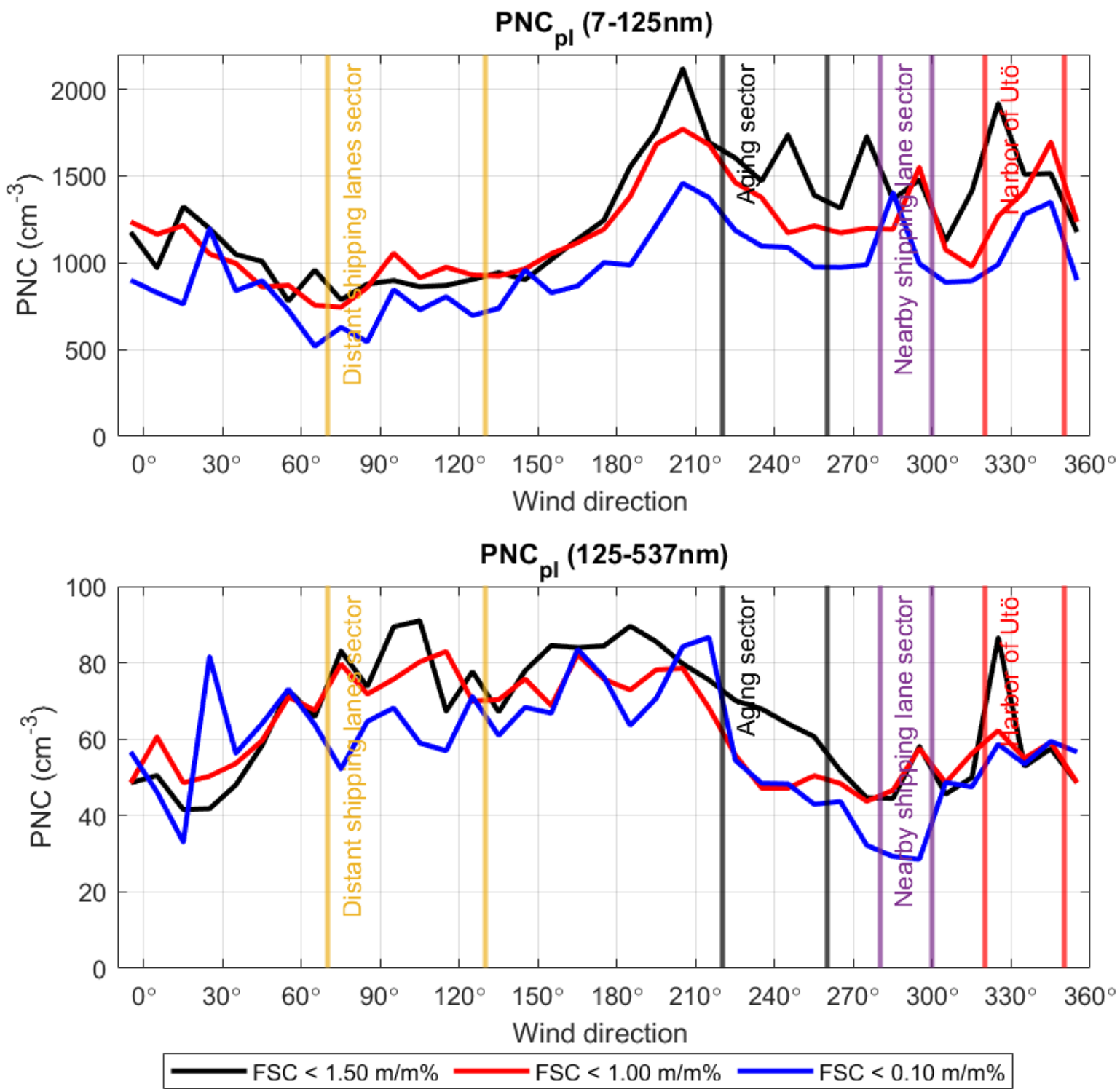

Figure S4: Average particle number concentrations of the plume particles $\left(\mathrm{PNC}_{\mathrm{pl}}\right)$ in size range 7-125 $\mathrm{nm}$ (upper panel) and 125$10537 \mathbf{~ n m}$ (lower panel) for different FSC restrictions averaged for $\mathbf{1 0}^{\circ}$-sectors. Distant shipping lanes sector, ageing sector, nearby shipping lane sector, and harbor of Utö are marked with vertical line pairs. 

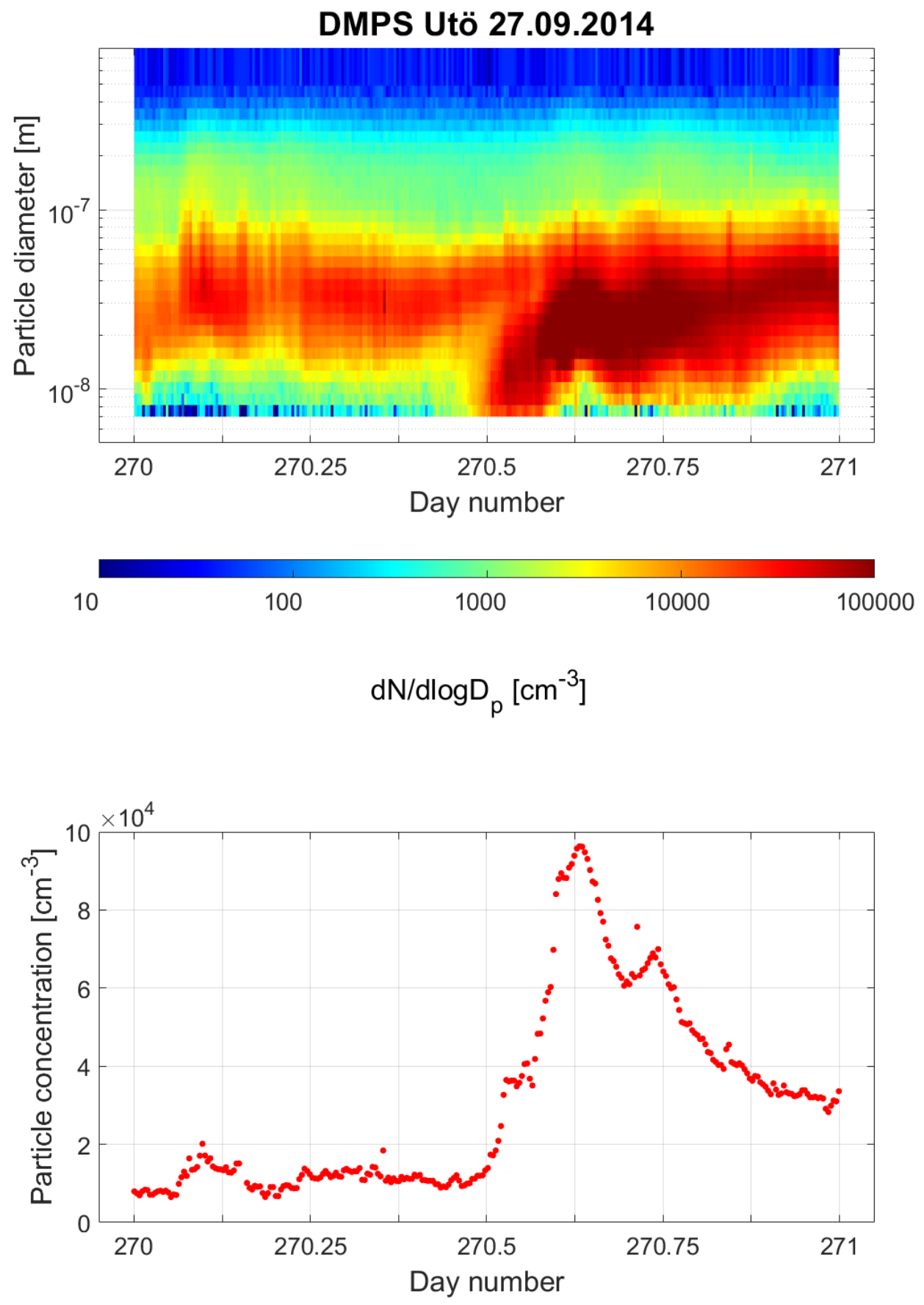

Figure S5: An example size distribution (upper) and particle concentration (below) of intense nucleation event in 2014. 
$\mathrm{FSC}<1.50 \mathrm{~m} / \mathrm{m} \%$

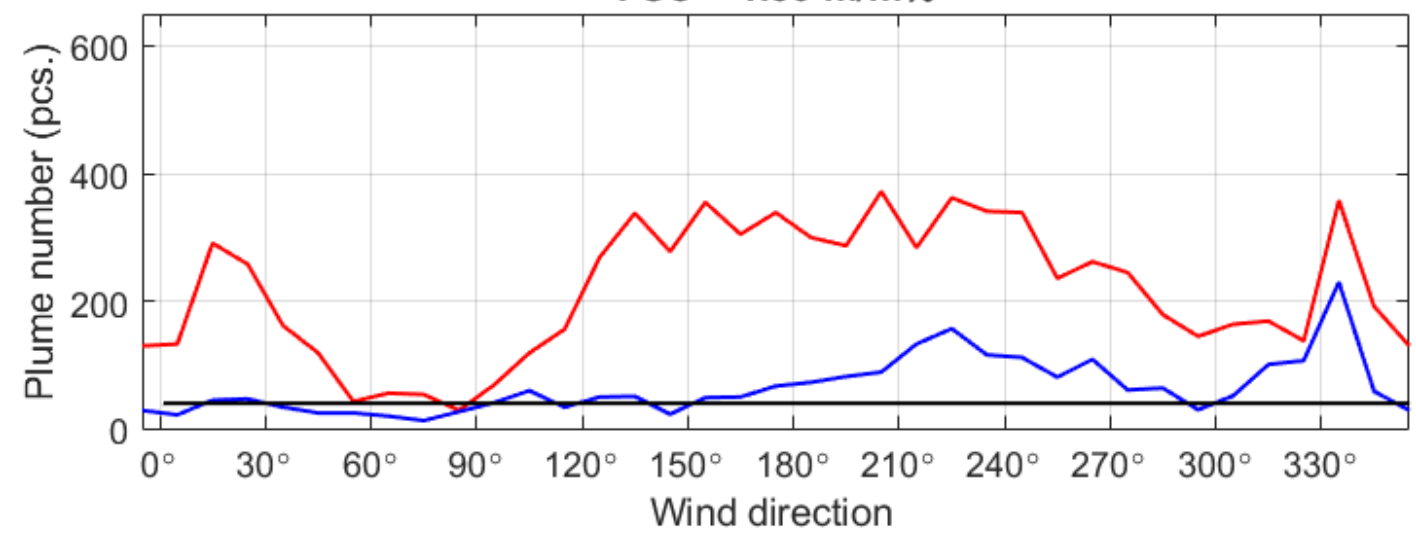

FSC $<1.00 \mathrm{~m} / \mathrm{m} \%$

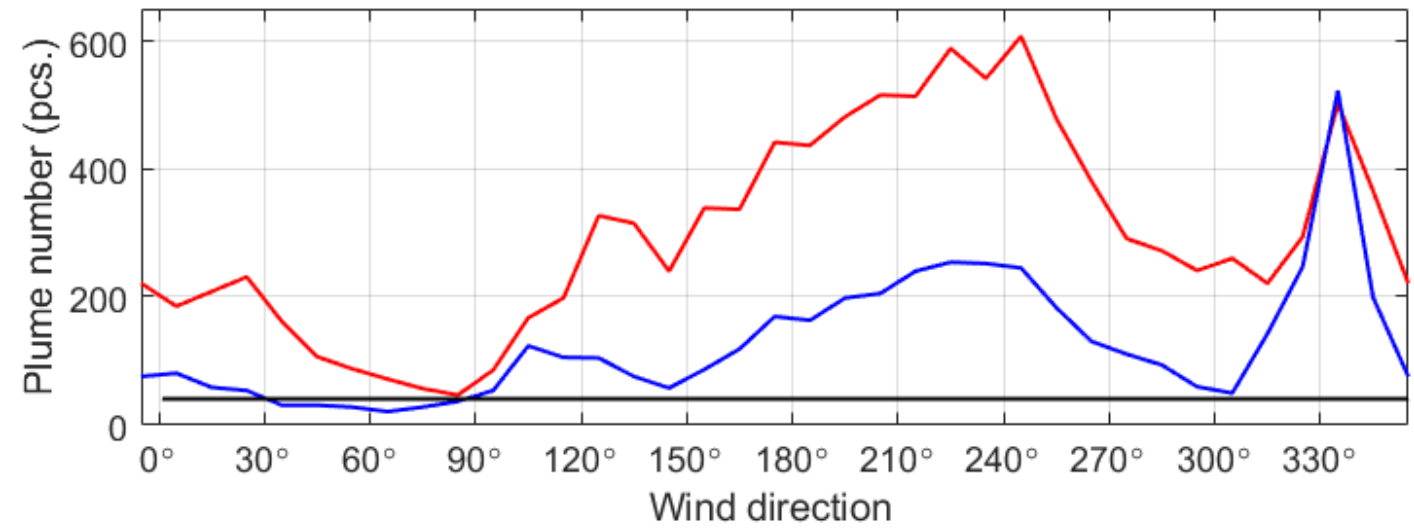

FSC $<0.10 \mathrm{~m} / \mathrm{m} \%$

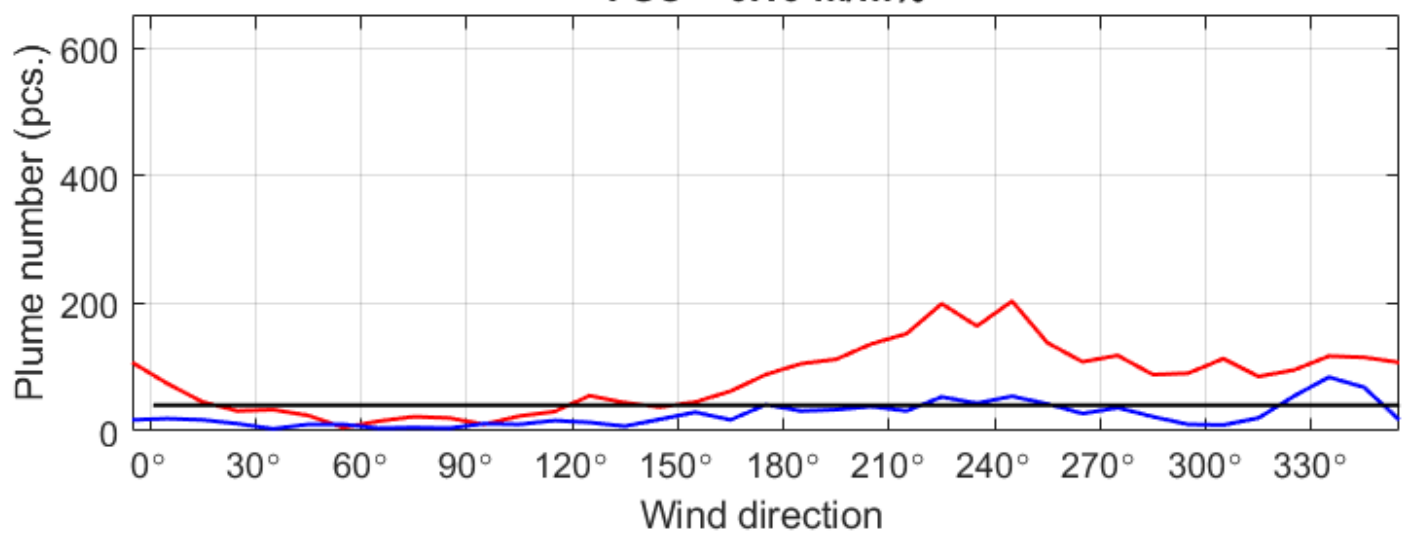

Nighttime

Daytime

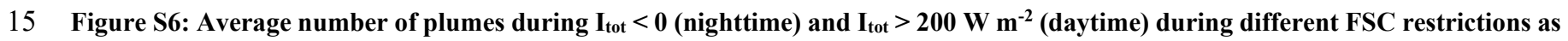
a function of wind direction. The black line marks the limit of 40 observed plumes per $10^{\circ}$ sectors. 

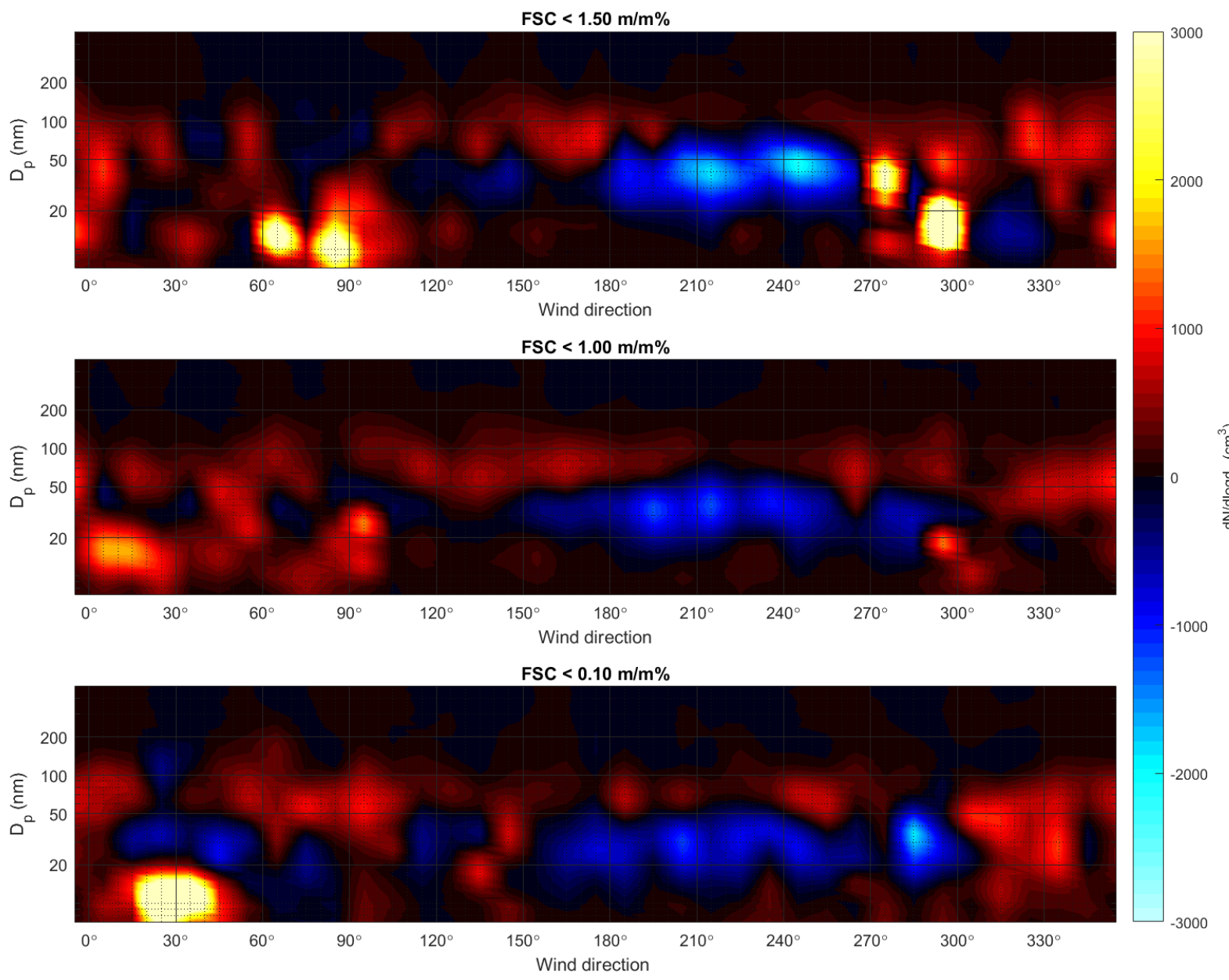

Figure S6: Average change caused to NSDpl by sunlight from different wind directions during the different FSC restrictions 


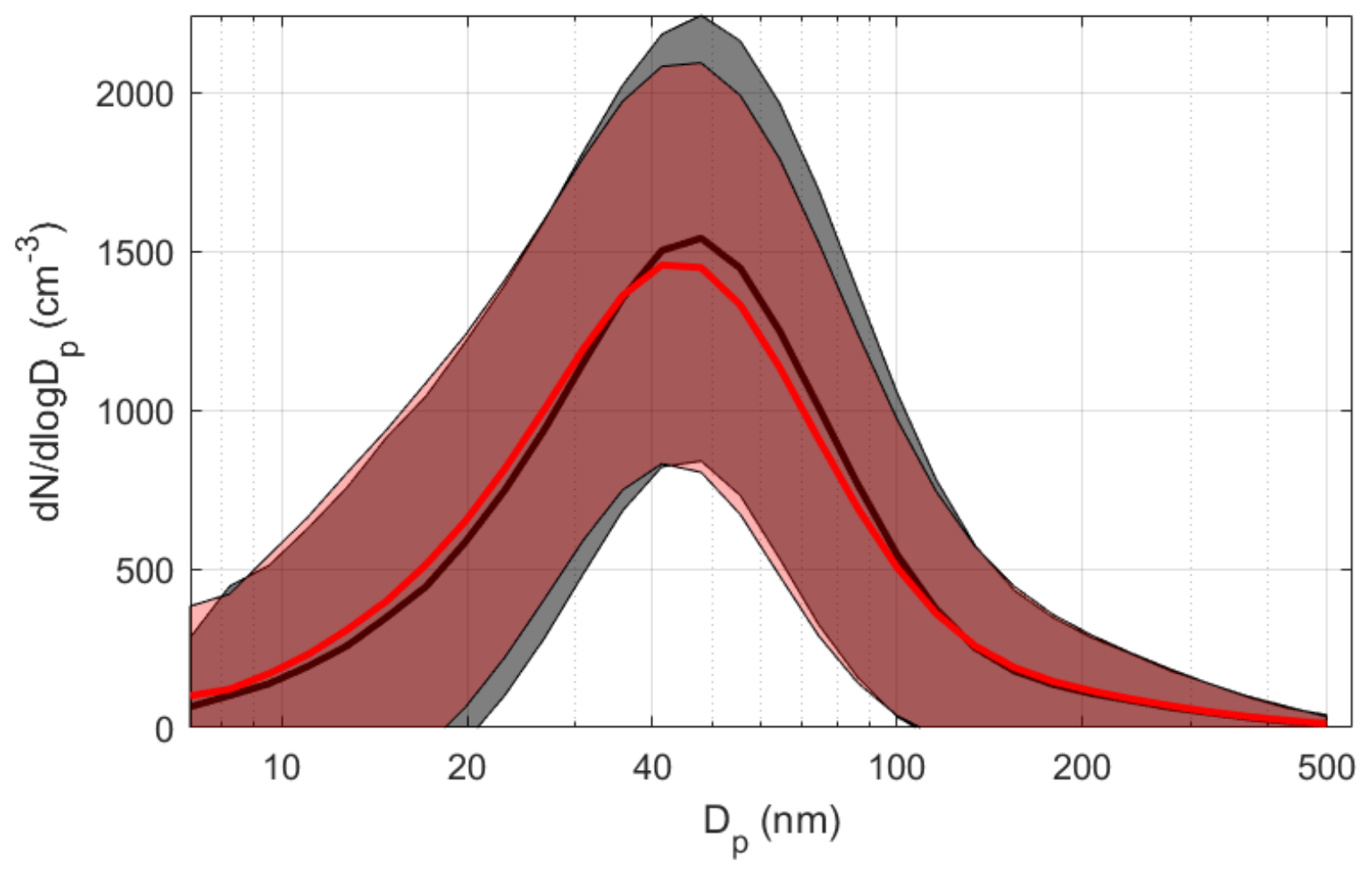

- Plumes without first and last measurement cycles

All plumes

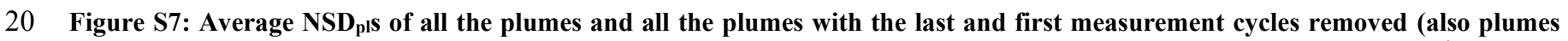
with only one measurement cycle removed). Individual $\mathrm{NSD}_{\mathrm{pls}}$ have been normalized to a total concentration of $1000 \mathrm{~cm}^{-3}$.

\section{Error caused by lengthy measurement cycles of the DMPS}

Because of the relatively long measurement cycle of the DMPS (5 min $20 \mathrm{~s}$ ), 36.4\% of the measured plumes were shorter than one measurement cycle and $63.8 \%$ were maximum of two measurement cycles long. Also, for the rest of the plumes, every plume has to have ended and started during the last and first measurement cycles. This causes an error to PNC $\mathrm{pl}_{\mathrm{pl}}$ $\mathrm{NSD}_{\mathrm{pl}}$ of an individual plume as the whole $\mathrm{NSD}_{\mathrm{pl}}$ is not measured during these cycles. As the particle sizes are scanned from small particles to large, in the first cycle the small particles of the $\mathrm{NSD}_{\mathrm{pl}}$ are not measured and during the last measurement cycle, the large particles of the $\mathrm{NSD}_{\mathrm{pl}}$ are not measured. This also causes error in correcting multiply charged particles, as, 
during the first measurement cycle, only the $\mathrm{PNC}_{\mathrm{pl}}$ of the larger particles is measured. Therefore, a large fraction of the

30 measured $\mathrm{PNC}_{\mathrm{ppl}}$ of smaller particles is considered as multiply charged large particles, and the $\mathrm{PNC}_{\mathrm{pl}}$ of small particles is decreased even further. During the last measurement cycle, the $\mathrm{PNC}_{\mathrm{pl}}$ is vice versa overestimated for the smaller particles as the low $\mathrm{PNC}_{\mathrm{pl}}$ of the large particles causes a too low estimate for the number of double-charged particles measured at the smaller particle sizes, which falsely increases the $\mathrm{PNC}_{\mathrm{pl}}$ of small particles. However, as these effects are opposite and counteract each other, the rather large data set renders the error to be small after the statistical analysis. The inversion routines

35 of the DMPS are discussed in more detail in (Pfeifer et al., 2014). To estimate the error caused by the first and last measurement cycles, $\mathrm{NSD}_{\mathrm{pl}}$ were drawn for all plumes and the plumes with the last and first measurement cycles removed. These are presented in the supplemental material (Fig. S8). The comparison shows that the influence of the first and last measurement cycles is not significant.

\section{References}

Pfeifer, S., Birmili, W., Schladitz, A., Müller, T., Nowak, A., and Wiedensohler, A.: A fast and easy-to-implement inversion algorithm for mobility particle size spectrometers considering particle number size distribution information outside of the detection range, Atmos. Meas. Tech., 7(1), 95-105, https://doi.org/10.5194/amt-7-95-2014, 2014. 